\title{
Advances and Challenges in Classical Galactosemia. Pathophysiology and Treatment
}

Journal of Inborn Errors of Metabolism \& Screening 2022, Volume 10: e20210026 DOI: https://doi.org/10.1590/2326-4594 JIEMS-2021-0026

\author{
Amanda R. Caro N.', Verónica Cornejo ${ }^{2}$ (D), \\ Johana M. Guevara-Morales ${ }^{1}$ (i) and Olga Y. Echeverri-Peña ${ }^{1}$
}

\begin{abstract}
Classical galactosemia is caused by the genetic deficiency of galactose-1-phosphate-urydyl-transferase resulting in clinical symptoms development during the first weeks of life including jaundice, hypotonia, lethargy, emesis, hepatomegaly, among others. Currently, dietary restriction of galactose is considered the standard for classical galactosemia management. For several years, severe dietary galactose restriction was considered necessary, implying restriction not only of dairy products, but also fruits, vegetables, legumes, and viscera. Such management failed to improve or prevent the appearance of long-term complications, by contrast, such restrictive approach may lead to nutritional deficiencies development. Thus, the last consensus suggests guidelines that are more flexible. In addition, the lack of knowledge regarding the physiopathology of the disease, and the toxicity threshold of the metabolites accumulated, make even more difficult to propose novel and more effective therapeutic approaches. This review summarizes the current state of knowledge regarding classical galactosemia in terms of physiopathology, long-term complications, newborn screening and genetic variants and their implications on galactosemia treatment, summed to the challenges that researchers working on this disease must address in future studies including the analysis of galactose content in foods, galactose tolerance threshold and search for novel therapeutic targets.
\end{abstract}

Keywords: Classical Galactosemia, Treatment.

\section{Introduction}

Galactosemia is an inborn error of carbohydrate metabolism. According to the enzyme altered in the Leloir pathway four different subtypes have been described [1-2]. Classical galactosemia is considered the most severe, and common condition, with a variable incidence according to the geographic area. In Latin-American countries, newborn screening is highly heterogeneous and limited information has been reported, in most cases pilot or short-term studies [3-6]. However, in Cuba and Ecuador, there are estimated reports of 1:101.065, and 1:131.579 respectively [7-8]. In Western countries, the reported incidence varies from 1: 16,000 to 1: 60,000 live births, reaching up to 1:480 in specific Irish population groups [9-11].

Classical galactosemia results from galactose-1-phosphate uridylyl transferase enzyme deficiency, which generates the accumulation of toxic metabolites and a neonatal clinical onset after breast milk or milk formulas intake. Main signs and symptoms include feeding difficulties, growth delay, hepatomegaly, jaundice, hypotonia, lethargy, emesis, renal tubular damage, and cataracts $[2,11]$.
Acute symptomatology can be reversed using galactose restriction. However, treatment does not prevent long-term complications such as premature ovarian failure, neurological manifestations, behavioral alterations, and decreased bone mineral density which have been reported to occur with different degrees of severity $[2,11]$. Several publications suggest that such complications may appear independent of the age of onset and treatment adherence [2,11-17]. Over time, patients may have difficulties in learning and language (verbal dyspraxia and dysarthria), also they frequently develop tremors and, to a lesser

\footnotetext{
${ }^{1}$ Universidad Javeriana, Facultad de Ciencias. Pontificia, Instituto de Errores Innatos del Metabolismo, Bogotá, Colombia.

¿Universidad de Chile, Instituto de Nutrición y Tecnología de los Alimentos, Laboratorio de Genética y Enfermedades Metabólicas, Santiago, Chile.
}

Received July 08, 2021. Accepted for publication December 21, 2021

\section{Corresponding Author:}

Olga Y. Echeverri-Peña

E-mail: oyecheve@javeriana.edu.co 
extent, ataxia and dystonia $[11,14]$. Subsequently, in adulthood, patients develop a complex neuropsychological phenotype, which appears more severe in men, and that is characterized by anxiety, depression, and difficulties to recognize complex facial emotions such as anger, surprise, fear, and disgust [18]. Together, these clinical signs affect patient's quality of life and can contribute to the disturbances in social interaction reported in this population [15,18-19]. All the above demonstrates that the exact pathological mechanisms involved in the disease are still unknown, despite the development of animal models; in vitro and descriptive studies; as well as interventions in cohorts of patients with classical galactosemia, have helped to strengthen our understanding of different molecular, clinical, and metabolic aspects of the disease [9,14,20-23]. Furthermore, given the poor response of long-term complications to nutritional treatment, novel therapeutic strategies are needed [1-2]. This review summarizes the current state of knowledge regarding classical galactosemia in terms of physiopathology and its implications on galactosemia treatment, pointing out current challenges that should be addressed in order to improve our understanding of galactosemia pathological mechanisms and potentiate the development of novel therapeutic strategies.

\section{Galactose Metabolism}

After linked galactose is hydrolyzed in the small intestine, it passes through the enterocyte using SGLT1 and GLUT2 transporters [2]. Subsequently, galactose arrives via porta to the liver, where $\beta$-D-galactose enters through the GLUT2 transporter to be metabolized in the Leloir pathway (galactose catabolic pathway). This pathway initiates with the enzyme galactose mutarotase (GALM) which transforms $\beta$-D-galactose to $\alpha$-D-galactose, this configuration change is required to allow the action of galactokinase (GALK), galactose-1-phosphate uridyltransferase (GALT), and galactose-4-epimerase (GALE) enzymes, in order to synthesize glucose 1-phosphate and UDP-glucose (Figure 1). Finally, glucose-1-phosphate can be integrated to other metabolic pathways, using the enzyme phosphoglucomutase, while UDPhexoses are involved in glycosylation reactions (Figure 1) [1-2].

Different studies allowed the identification of three alternative metabolic routes to the Leloir pathway: galactose to galactitol reduction through the polyol route; oxidation of galactose to galactonate and GALK-dependent derivation for UDP-galactose synthesis, known as the pyrophosphorylase pathway (Figure 1) $[1-2,24]$. However, the latter seems to have low activity in humans, compared to GALT [25-26].

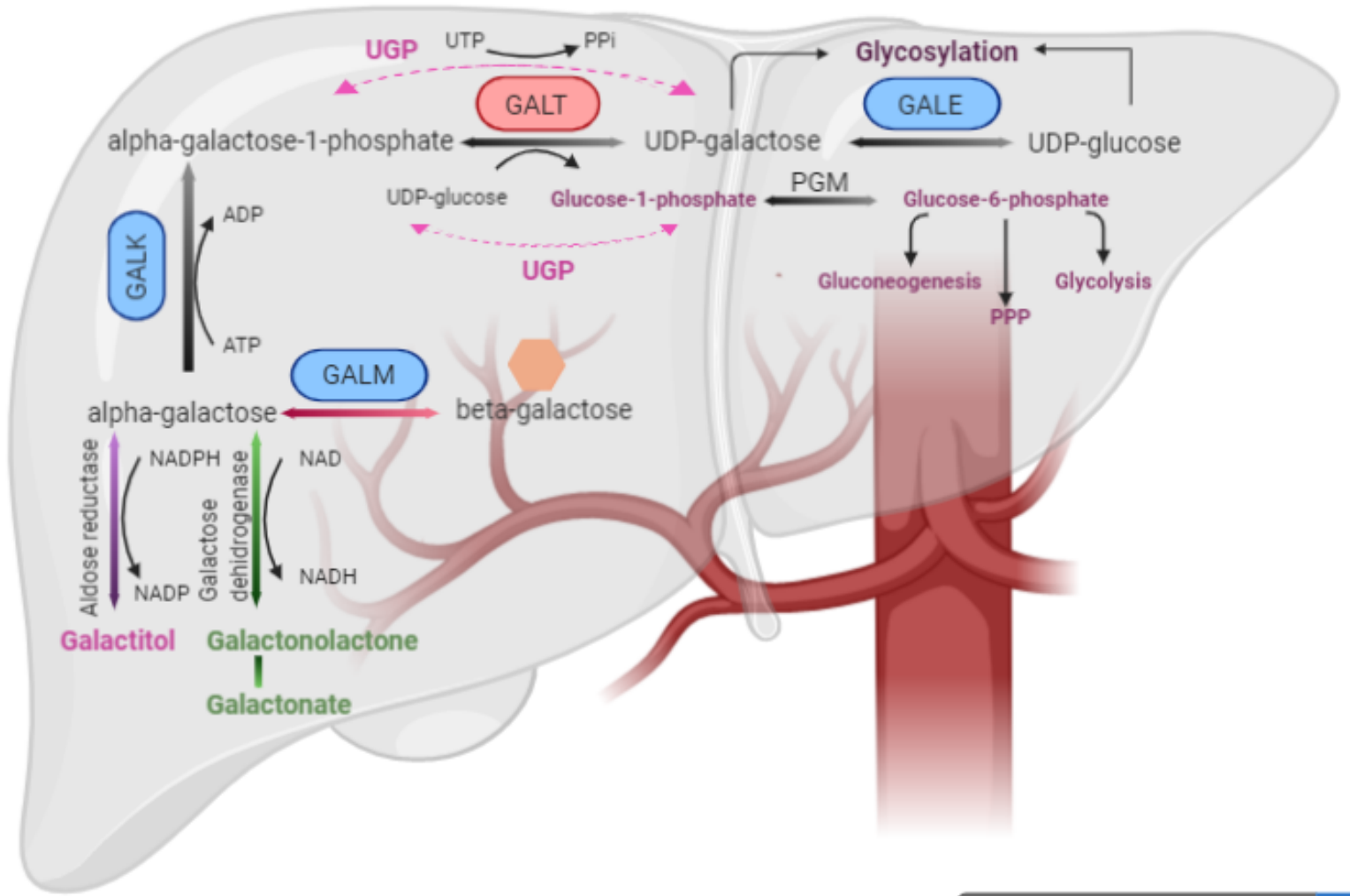

Created in BioRender.com bio

Figure 1. Galactose metabolism (Leloir pathway and other routes). Galactose main metabolic pathway or Leloir pathway (blue color), involves the following enzymes: galactose mutarotase (GALM), galactokinase (GALK), galactose-1-phosphate uridyltransferase (GALT), galactose-4-epimerase (GALE). GALT reaction product, glucose-1-phosphate, requires the action of phosphoglucomutase (PGM) to take other metabolic pathways. In the case of GALT deficiency (red), alternative pathways are activated involving different enzymes: aldose reductase (purple), galactose dehydrogenase (green) and UDP glucose/hexose pyrophosphorylase (UGP) (pink). 


\section{Clinical Manifestations and Pathophysiology of Galactosemia. Emerging Advances and Needs}

Galactose is considered essential for maintaining energy metabolism balance during the first months of life since it is incorporated faster than glucose for glycogen synthesis [27-28]. Lactose contributes to around $40 \%$ of the total energy gain in infants and about $2 \%$ in adults [29]. Some authors suggest that when GALT is deficient, there could be increased energy requirements and usage of other energy substrates such as glucose, sucrose, and fructose [30-31]. Therefore, the absence or limited intake of other carbohydrates in early infancy could compromise even more the energy metabolism within the body in galactosemia, especially under catabolic stress. This mechanism may contribute to energy and liver failure in childhood and could explain the acute toxicity syndrome reported in patients [30-31].

Researchers have postulated two hypotheses to explain galactosemia pathophysiology: First, increased galactose-1phosphate levels lead to phosphate sequestering and subsequent dephosphorylation of other compounds not involved in energy production [32]. The second hypothesis suggests that energy production is compromised due to inhibition of enzymes involved in glucose metabolism (glucose-6-phosphatase, phosphoglucomutase, UDP-glycogen phosphorylase, glucose6-phosphate dehydrogenase) by galactose-1-phosphate [32-33]. In vitro studies have supported the second hypothesis, by demonstrating such inhibition of pyrophosphorylase [21]. Moreover, it has been reported that increased levels of galactose-1phosphate may inhibit galactosyl transferases and thus, promote glycosylation defects [32-34].

In addition, galactitol accumulation has also been associated with galactosemia pathophysiology by generating a hyperosmotic effect (resulting in cataracts formation) and favoring oxidative stress secondary to NADPH depletion and free radical formation $[1-2,32]$. In fact, oxidative stress, as a pathological mechanism, has been described in animal models and patient studies that show increased oxidative stress markers and decreased activity of enzymes involved in oxidative stress response (v.g. catalase, glutathione peroxidase, and NADPH oxidase) $[1,12,35-36]$. These findings suggest that the production of toxic metabolites in galactosemia could generate greater sensitivity to oxidation damage [1,12,35-36].

Although, initially, the high amounts of galactitol and galactose1-phosphate seemed to explain the pathophysiology of the disease, the high clinical heterogeneity, and the poor biochemical-clinical correlation indicate that understanding galactosemia complexity requires exploring the role of other metabolites and considering new pathways in the biochemical cascade. A good example of this is the potential role of galactonate. It has been postulated that galactonate can enter into the pentose-phosphate pathway to be transformed in xylose, without generating toxicity. Despite this, only the first enzyme of this metabolic route has been reported in humans and there is no further evidence of the role of such pathway in galactosemia [37-41].

In addition, in mouse fibroblasts, GALT deficiency lead to signaling pathways alteration possibly associated with glycosylation defects that induce negative regulation of phosphatidylinositol-4,5-biphosphate 3-kinase (PI3K) / protein kinase B (Akt). This protein is necessary for tissue growth and proliferation and some authors have suggested this as the mechanism explaining the neurological alterations described in galactosemic patients [1].

Besides the above-mentioned mechanisms, the contribution of other metabolic actors to acute and chronic toxicity is still unclear, including the role of lysosomal hydrolysis of glycoconjugates as endogenous galactose production [2].

Patients with classic galactosemia usually present longterm complications such as neurological, cognitive, behavioral alterations, premature ovarian failure, and low bone mineral density [11]. Some authors have proposed that such complications can also be related to glycosylation defects due to UDP-hexoses deficiency, since GALE reaction is insufficient to generate enough amounts of UDP-galactose. It has been suggested that UDPhexose deficiency could lead to alterations in myelin formation, follicle-stimulating hormone, and collagen $[1,16,22]$.

The most frequently reported neurological complications include tremors, motor abnormalities, ataxia, dystonia, language and speech disorders that present with different degrees of severity $[11,17,42]$. Although the mechanisms associated with these complications are not fully understood, some studies have established approaches to pathophysiology. In the study reported by van Erven., et al (2017), the functionality of neurological networks was evaluated in adolescents with classic galactosemia at rest, finding alterations in the functional networks of the insula, which are considered important for sensory integrationmotor [43]. In addition, associations have been reported between tremor severity and low gray and white matter myelin content (assessed by resonance), which could be associated with deficient glycolipid production due to lack of UDP-sugars [21,44]. However, longitudinal studies are required to establish whether changes in gray and white matter are the result of early dysmyelination or progressive neurodegenerative disease [44].

Cognitive and behavioral traits commonly reported include decreased Intelligence Quotient (IQ), speed of information processing and perception of space, symptoms of anxiety and depression, these being variable aspects in terms of presence and severity, which can compromise the quality of life and social skills of individuals with classic galactosemia [11,18,45-46]. A decrease in IgG N-glycan sialylation, detected in individuals with classic galactosemia, could partially explain the long-term results, mentioned above [47]. Sialic acid is a sugar required for the synthesis of glycolipids, which is part of complex N-glycans that are part of the structure of the hippocampus [47-48]. $\mathrm{N}$-glycans are known to be necessary to carry out functions such as neurogenesis, synapses, and memory formation [48]. 
The decrease in sialylation could be related to the dysregulation of genes, which code for sialyltransferases in patients [47]. Additional studies are required to define whether cognitive and behavioral outcomes evolve in the long term and what are the causes of their appearance [46].

Currently, the exact moment in which premature ovarian failure occurs and its pathophysiology is not clear, although it is suggested that factors such as circulating levels of leptin and increased expression of genes involved in inflammation pathways may play a potential role [49]. The results in children and adults with galactosemia show an alteration in the regulation of leptin metabolism, an important hormone for the release of luteinizing hormone and stimulating follicle [49]. Furthermore, the findings in patients aged 17 - 51 years suggest that there is a negative correlation between leptin levels and IgG galactosylation or testosterone levels in men [49].

Regarding long term complication related to bone health the literature reports alterations in height and growth rate and increased risk of low bone mineral density (BMD) [2,11]. A systematic review and meta-analysis of bone health in individuals with galactosemia concluded that BMD seems to be slightly affected, based on the results of cross-sectional studies that included a population between 2.5 and 59 years old [50]. However, it is estimated that $10-25 \%$ of the population with this disease would be at risk of developing low BMD (Z-score $\leq-2)$. The studies included in the review reported calcium levels within the normal range and vitamin D levels with a trend towards the lower limit, although these studies presented differences in the quantification method and measurement ranges [50]. Although not fully understood, alterations at the bone level have been related to nutritional calcium and vitamin $\mathrm{D}$ deficiencies due to galactose restriction $[2,11]$. However, some authors suggest that other intrinsic factors associated with the pathology must be involved that could be related to low estrogen concentrations due to premature ovarian failure, less physical activity due to motor and neurological disorders, or intrinsic defects in the collagen [22,50-51].

\section{Treatment and Outcome. Looking for a Novel Therapeutic Approach}

Galactose is an aldohexose found either free or within the structure of complex carbohydrates such as oligosaccharides, polysaccharides, and some glycoconjugates like glycoproteins and glycolipids [2]. The main dietary sources of free galactose are dairy products, milk-based formulas and breast milk which contain high amounts of lactose (a disaccharide formed by galactose and glucose) [29]. For instance, it has been estimated that $100 \mathrm{~g}$ of cow's milk provides $2400 \mathrm{mg}$ of free galactose, while the same amount of cheese provides around $200 \mathrm{mg}$ approximately (Table 1). In addition, other sources of free galactose include fruits, vegetables, tubers, legumes, and soy products (Table 1) [29,31-32,52].
As mentioned above, galactose can also be found forming oligosaccharides like raffinose, stachyose, and verbascose that are present in legumes [29]; polysaccharides like arabinogalactans in vegetables; galactomannans, used as food additives for increase viscosity; galactolipids, galactosylcerebrosides, and gangliosides present in foods like viscera $[29,31-32,52]$.

Nutritional treatment is still considered as the first-line therapeutics for classical galactosemia. It is effective for preventing or reversing the early acute symptomatology associated to galactose consumption during the first months of life [2]. In general, nutritional intervention during the first six months of life includes the prescription of soy-based formulas or elemental formulas as the only feeding source [31]. However, with the introduction of complementary foods, some controversies around nutritional indications arouse. Initially, the indication was to avoid completely dairy products and viscera, but after the presence of galactose (either free or conjugated) was evidenced in fruits, vegetables, and legumes dietary recommendations became more and more restrictive [31]. Nevertheless, some authors suggested that galactose present in these foods could not be digested and absorbed due to the absence of the enzymatic battery within the human gastrointestinal tract. Therefore, free galactose from these sources was more influenced by storage and maturation, suggesting that fruits, vegetables, and legumes could be included in the diet $[29,31]$. In addition, the consumption of mature cheeses was allowed considering their lower galactose content compared to yogurt and milk. In addition, this type of cheeses could then represent a good calcium source that could optimize the diet, although, galactose content may vary according to production conditions such as the microorganism strain used in the maturation process, artisanal versus industrialized conditions, and maturation time $[31,52]$. In this context, the studies demonstrate that it is necessary to consider the galactose composition of each food and factors that can alter it.

As mentioned above, together the lack of knowledge regarding the pathophysiology of galactosemia; the presence of galactose in fruits, vegetables, and legumes without precise information related to its availability in these foods; and the uncertainties about disease progression had led to the generation of two management trends. This is evidenced by the contrasting management indications observed in different specialized centers. In some cases, dietary intake of galactose is not quantified and vegetables are allowed in the diet arguing that it would prevent nutritional deficiencies that could arise from restricting such foods. On the other hand, some management centers indicate specific limits for dietary galactose intake that may vary according to the criteria of each professional [61-63]. Nevertheless, neither early and strict galactose restriction (dairy and non-dairy galactose restriction), nor adherence to diet seem to prevent the appearance of chronic complications $[11,17,62]$. In fact, reports from cohorts of patients following such diets showed an increased frequency of neurologic complications compared to patients following more flexible diets [2,11]. In addition, there is no evidence that a flexible diet is associated with the severity of long-term results, on the 
Table 1. Free galactose content of some foods.

\section{Food}

Dairy products

Strong Cheddar cheese

UK west Cheddar cheese

Gruyere cheese

Emmental / Swiss cheese

OAmerican parmesan cheese (10 months maturation)

American parmesan cheese (grated)

Cow's milk

Yogurt

Fruits (raw or processed)

Watermelon

Papaya

Kiwi

Blueberries

Pinapple

Pear

Strawberries

Banana

Apple

Melon

Vegetables (raw or processed)

Onion

Tomato

Brussels sprouts

Lettuce

Brocoli

Carrot

Fruit of vegetable juice

Tubers

Potato

Legumes

Chickpea (cooked)

Chickpea

Red beans

Green beans

Lentils

Peas

Soy products

Whole soybean

Soy milk

Tofu

\section{(mg/100g/ml of food)}

$9,5+/-17,9(<2,8-104,3)[31]$

$3,6(<2,8-11,4)[53]$

$4,1+/-1,2(<2,8-5,1)[31]$

$3,5+/-1,2(2,8-7,4)[31]$

$18,3+/-33,3(<2,8-156)$ [31]

$9,7+/-12,0(<2,8-23,6)[31]$

2400 [54]

1800 [54]

$9,7+/-7,9(1,0-44,5)[31]$

14,7 [55]

28,6 [55]

$9,8[55]-27,1[56]$

26,2 [55]

18,7 [56]

$7,3[55]$

4,6 [57]- 10,7 [58]

9,2 [55]

$8,3[55,59]$

$5,5[60]$

9,3 +/- 11,4 (ND-77,2) [31]

$5,1[55]-15,3$ [58]

$5,6[58]-13,3$ [56]

$9,2[55,59]$

$3,1[55]-7,8[58]$

$6,8[55]$

$6,2[55]$

$18,3+/-14(4,0-46,4)[31]$

$1,2[55]-10,7[58]$

$149,5+/-197(24,6-443,8)[31]$

443 [60]

153 [60]

5,5 [58]

115,8 [60]

11,8 [60]

43,8 [31]/ 44 [58]

$5,1+/-0,4(4,8-5,3)$ [31]

90 (dried weight) [31]

ND: Non detectable.

Galactose content of cheeses can vary depending on production conditions and maturation time. 
J. inborn errors metab. screen.

contrary, it seems to be related to a lower frequency of neurological complications [11,64-65]. In this sense, the last management guidelines recommend lifelong dietary restriction of dairy products, allowing free intake of any kind of fruits, vegetables, legumes, and non-fermented soy-based product [66]. Additionally, the consumption of mature cheeses (in which galactose content is lower than $25 \mathrm{mg} / 100 \mathrm{~g}$ of food) is allowed [66]. The latter has been promoted to optimize calcium intake in order to meet the recommendations for age, highlighting the need to monitor vitamin $\mathrm{D}$ and calcium levels and consider supplementation if needed $[51,66]$. Altogether, this evidence reinforces the need for establishing exogenous galactose (galactose from food) tolerance and its relationship with long-term complication [31,67]. On the other hand, variations in the complications of individuals with the same genotype suggest the influence of other factors, such as epigenetic mechanisms, on glycosylation or signaling pathways such as unfolded protein response (UPR), inositol and inflammation [49], for which the research has been aimed at evaluating management alternatives beyond diet $[11,68]$.

A limitation to optimize the treatment of the disease is the lack of precise biomarkers that can be used to monitor nutritional intervention and predict the risk of developing complications $[12,49]$. Currently biochemical follow-up of patients is performed by measuring eritrocitary galactose-1phosphate levels (Gal-1-P) with values below $5 \mathrm{mg} / \mathrm{dL}$ considered as the therapeutic range [13]. However, stabilization or even decrease of this metabolite over time in treated patients has been reported 12,14]. Furthermore, results regarding correlation between Gal-1-P and long-term complications onset or severity are contradictory $[12,14,69]$. Other galactose metabolites like galactitol, galactonate and their ratio have been suggested as potential biomarkers since they are highly accumulated in fluids from patients compared to controls [40,70]. However, poor correlation has been observed between these metabolites and with galactose plasma levels and GAL-1-P $[40,70]$. In fact, galactonate evaluation is rarely reported in literature and for galactitol, similar to the observed with Gal-1-P, results related to treatment response are controversial and high variations especially in urinary levels have been observed, therefore its clinical utility is considered limited [2,13-14,40,66,70-71]. Recently, analysis of glycosylation patterns of IgG N-glycans have been proposed as biomarkers, the wide spectrum of clinical results between individuals highlights the need to continue with this area of research $[12,67]$.

In this sense, there are still unresolved questions regarding whether it would be possible to reverse complications through frequent monitoring of biomarkers and adjustments of galactose consumption according to the result [67]. In addition, there is uncertain if there are critical periods in which nutritional intervention is necessary and how dietary characteristics beyond galactose content (v.g. energy and micronutrient intake) may influence pathology course. However, addressing these aspects implies developing a rigorous evaluation of the diet [61]. Therefore, it might be necessary to resume analyzes of galactose content in foods, to evaluate the consumption, since reliable data regarding galactose content of some foods is still limited [61]. The relevance of this arises from factors such as the varieties of food available in each country and the reports on changes in the amount of free galactose, due to aspects related to farming; time and conditions of food storage; and processing [57-58]. These analyzes could help to define more precisely the amount of galactose that patients consume and help to establish whether there is a tolerance threshold, that is, an amount of galactose exogenous to the individual, which can optimize the glycosylation profile without generate signs of intoxication $[11,61,67]$. It is possible that if galactose consumption is not established precisely, it could be masking its role in the clinical picture of the disease and its relationship with metabolic changes.

Due to the above-mentioned limitations of nutritional management, it is becoming more relevant the idea to widen the therapeutic approach in galactosemia. In this line, efforts are being done to develop pharmacological strategies including: pharmacological chaperones to improve stability and therefore residual GALT enzyme activity; GALK inhibitors; research on the efficacy of antioxidant therapy and exploration of mechanisms for overexpression of UGP pyrophosphorylase (which seems to prevent toxicity in in vitro models) [1-2,72].

\section{Galactosemia Variants}

According to the GALT database, 363 different molecular variations have been reported in the GALT gene (318 pathogenic variants and 45 considered benign). Most pathogenic variants are missense mutations and are distributed throughout the gene. Their frequency has been widely studied demonstrating ethnic and geographic differences [73-75]. For instance, p.Q188R is the most common allele in white population (6-10), whereas p.S135L and IVS2-2A $>\mathrm{G}$ variants are frequently reported in patients of African and Hispanic origins, respectively [73,76-78].

In general, the term "galactosemia variant" has been used to refer to GALT mutations that lead to high, although variable, residual activity. Different variants have been described up to date including: Los Angeles, Chicago, Renes, Indiana, Muenster, Negro, and Duarte, with the latter being the most common $[2,73,79-80]$. Some of these variants seem to present faster treatment response and have been associated with better longterm outcomes, however, there is still not enough evidence to make recommendations regarding if to establish or not a nutritional intervention or define specific indications [73].

Duarte variant galactosemia is the result of a partial deficit of GALT (14 to $25 \%$ of residual activity approximately), characterized by a higher galactose tolerance compared to the observed in classical galactosemia $[2,73,81-82]$. Duarte variant is a biochemical and genetic phenotype, in which at least five genetic variations have been described: 4bp $5^{\prime}$ del $+\mathrm{N} 314$ / Q188R mutation, c. 378-27G $>C$, c. $507+62 \mathrm{G}>\mathrm{A}$, and c. $508-24 \mathrm{G}>\mathrm{A}$, and the promoter deletion c.-119-116delGTCA [74]. The apparent asymptomatic phenotype displayed by individuals with this 
variant, despite the evidence of biochemical abnormalities and the accumulation of toxic metabolites (reaching lower levels compared to classical galactosemia), has resulted in different opinions regarding its management [83-84]. Some authors consider that the potential occurrence of long-term complications comparable to those observed in classical galactosemia is enough argument for indicating galactose restriction until normalization of biochemical parameters is achieved [83-84]. However, descriptive studies show that long-term complications, like ovarian failure, are not observed in women presenting Duarte variant, as well as the absence of developmental delay despite galactose exposure from infancy in Duarte variant individuals [83]. Other experts suggest that without clarity regarding galactose toxicity threshold and lacking information of longterm evolution of individuals presenting Duarte variant, there is not enough evidence to implement a nutritional intervention $[66,83]$. Currently the consensus among researchers is that the Duarte variant does not require special treatment since it has not been documented that the lack of it results in developmental abnormalities or additional risks $[74,76,85-86]$.

Despite the above-mentioned divergences in terms of management indications, it is recommended to follow galactose1-phosphate levels in individuals presenting Duarte variant and increase follow-up frequency (each four to six months) if galactose restriction is introduced [84]. The setpoint to consider galactose restriction is not well defined, however, in countries like the Netherlands, the indication is to treat and follow individuals with residual activities lower than 15\% [87].

\section{Newborn Screening}

Up to now, the impact of newborn screening on the long-term outcome in galactosemia is still unclear. However, descriptive studies show its impact on mortality and acute symptomatology by favoring an early onset of nutritional management especially if results are available within the first week of life [87-89]. Moreover, early detection could have an effect on patient's quality of life. Therefore, it is necessary to develop prospective studies that address long-term outcomes in patients detected by newborn screening $[11,87,89]$.

Besides the implications that newborn screening may have in terms of the treatment, such screening is controversial from a diagnostic point of view due to the wide variety of laboratory approximations that are available including the measurement of different metabolites (Total galactose, galactose-1-phosphate, GALT activity) and differences among cutoff values among programs [90]. In addition, the experience reported from the Netherlands points out the necessity for evaluation and optimization of detection methods to improve effectiveness and avoid false-positive rates considering the family and psychosocial implications that early detection of benign galactosemia variants, like Duarte, may generate $[87,90]$.

\section{Conclusion}

The development of a high number of studies using animal models, descriptive and intervention approaches, have allowed the formulation of diverse hypothesis around the pathophysiology of classical galactosemia which consider the accumulation of toxic metabolites as well as secondary defects on glycosylation. However, one of the main challenges in galactosemia is to fully understand the pathophysiological mechanisms as a starting point for identifying novel biomarkers and therapeutic objectives, address long-term complications, and better define therapeutic approaches. This implies to understand the contribution of factors such as endogenous galactose production; exogenous galactose tolerance level; the contribution of other metabolic actors besides Leloir intermediaries to acute and chronic toxicity; the role of epigenetic and environmental factors; among others [18].

According to the last management guidelines, dietary galactose restriction (allowing fruits, vegetables and some mature cheeses) is still the first line management option although aspects related to galactose bioavailability are still unclear. In addition, nutritional treatment is not effective to prevent long term complications highlighting the need for further studies that may guide the development of novel strategies, in the context of personalized treatment, that consider clinical and therapeutic aspects that arise with each publication. In fact, according to the NIH, 10 studies are currently registered in different stages of development, five of them focusing on the search for new treatments or the improvement of existing ones. The other five have to do with the study of disease natural history and its possible long-term consequences or in specific situations such as pregnancy [91].

In the context of the nutritional treatment, there is still the need for studies aimed to quantify foods galactose content taking into account factors such as production, storage and maturation time. Moreover, it is important to define tolerance levels and galactose requirements according to age as well as follow up biomarkers that allow to better define nutritional prescriptions. Finally, all the above mentioned should be considered also for galactosemia variants since there is still a lack of consensus regarding their treatment indications.

\section{Declaration of Conflicting Interests}

The authors declare no competing interests.

\section{References}

1. Haskovic M, Coelho AI, Bierau J, et al. Pathophysiology and targets for treatment in hereditary galactosemia: A systematic review of animal and cellular models. J Inherit Metab Dis. 2020;43(3):392-408. doi:10.1002/jimd.12202

2. Coelho AI, Rubio-Gozalbo ME, Vicente JB, Rivera I. Sweet and sour: an update on classic galactosemia. J Inherit Metab Dis. 2017;40(3):325-342. doi:10.1007/s10545-017-0029-3 
3. De Céspedes C, Saborío M, Trejos R, Abarca G, Sánchez A, Rojas L. Evolution and innovations of the National Neonatal and High Risk Screening Program in Costa Rica. Rev Biol Trop. 2004:52(3):451-466. doi:10.15517/rbt.v1i2.15278

4. Medina DAC, Oldak KB, Vela AM, Ibarra GI, Fernández LC, Oldak SD. Alta sospecha de enfermedades metabólicas congénitas en la población de ascendencia judía del Hospital Ángeles Lomas. Acta Med. 2017;15(1):32-35. doi:10.35366/70731

5. Navarrete-Martínez J, Cervantes-Barragán D, LimónRojas A, et al. (PDF) Incidencia de errores innatos del metabolismo, endocrinopatías, hemoglobinopatías y otros desórdenes detectados por tamiz metabólico ampliado. Rev Médica Petróleos Mex. 2018;11:72-83. https://www. researchgate.net/publication/339565795_Incidencia_ de_errores_innatos_del_metabolismo_endocrinopatias_ hemoglobinopatias_y_otros_desordenes_detectados_por_ tamiz_metabolico_ampliado. Accessed November 3, 2021.

6. Cruz-Camino H, Martínez Cervantes HA, Cantú-Reyna C, Vázquez-Cantú DL, Zea-Rey A, Gómez Gutiérrez R, Vera Delgado JA. Incidencia de errores innatos del metabolismo y otros trastornos detectados en un programa de cribado metabólico neonatal ampliado de un grupo mexicano de hospitales. Acta Pediatr Esp. 2020;78(3-4):e25-e32.

7. González Reyes CE, Castells EM, Frómeta A, et al. SUMA technology and newborn screening tests for inherited metabolic diseases in Cuba: an overview of the first 30 years. J Inborn Errors Metab Screen. 2016;4:1-9. doi:10.1177/2326409816661356

8. Pozo-Palacios J, García-Díaz G, Cruz F, Porras F, Heras J, Cano-Pérez E. Spatial distribution of congenital disorders diagnosed by the Newborn Screening Program in Ecuador. J Inborn Errors Metab Screen. 2021;9:e20200016. doi:10.1590/2326-4594-JIEMS-2020-0016

9. Jumbo-Lucioni PP, Parkinson WM, Kopke DL, Broadie K. Coordinated movement, neuromuscular synaptogenesis and trans-synaptic signaling defects in Drosophila galactosemia models. Hum Mol Genet. 2016;25(17):36993714. doi: $10.1093 / \mathrm{hmg} / \mathrm{ddw} 217$

10. Timson DJ. The molecular basis of galactosemia Past, present and future. Gene. 2016;589(2):133-141. doi:10.1016/j.gene.2015.06.077

11. Rubio-Gozalbo ME, Haskovic M, Bosch AM, et al. The natural history of classic galactosemia: lessons from the GalNet registry. Orphanet J Rare Dis. 2019;14(1):86. doi:10.1186/s13023-019-1047-z

12. Welsink-Karssies MM, Ferdinandusse S, Geurtsen GJ, et al. Deep phenotyping classical galactosemia: clinical outcomes and biochemical markers. Brain Commun. 2020;2(1):fcaa006. doi:10.1093/BRAINCOMMS/FCAA006
13. Berry GT. Classic galactosemia and clinical variant galactosemia. In: Adam MP, Ardinger $\mathrm{HH}$, Pagon RA, Wallace SE, Bean LJH, Stephens K AA, eds. GeneReviews ${ }^{\bullet}$. Seattle, WA: University of Washington; 2000. https:// pubmed.ncbi.nlm.nih.gov/20301691/. Accessed December $14,2020$.

14. Yuzyuk T, Viau K, Andrews A, Pasquali M, Longo N. Biochemical changes and clinical outcomes in 34 patients with classic galactosemia. J Inherit Metab Dis. 2018;41(2):197-208. doi:10.1007/s10545-018-0136-9

15. Korner M, Kälin S, Zweifel-Zehnder A, Fankhauser N, Nuoffer J-M, Gautschi M. Deficits of facial emotion recognition and visual information processing in adult patients with classical galactosemia. Orphanet J Rare Dis. 2019;14(1):56. doi:10.1186/s13023-019-0999-3

16. Ridel KR, Leslie ND, Gilbert DL. An updated review of the long-term neurological effects of galactosemia. Pediatr Neurol. 2005;33(3):153-161. doi:10.1016/j. pediatrneurol.2005.02.015

17. Kuiper A, Grünewald S, Murphy E, et al. Movement disorders and nonmotor neuropsychological symptoms in children and adults with classical galactosemia. J Inherit Metab Dis. 2019;42(3):451-458. doi:10.1002/JIMD.12054

18. Waisbren SE, Potter NL, Gordon CM, et al. The adult galactosemic phenotype. J Inherit Metab Dis. 2012;35(2):279286. doi:10.1007/s10545-011-9372-y

19. Hoffmann B, Dragano N, Schweitzer-Krantz S. Living situation, occupation and health-related quality of life in adult patients with classic galactosemia. J Inherit Metab Dis. 2012;35(6):1051-1058. doi:10.1007/s10545-012-9469-y

20. Berry GT, Reynolds RA, Yager CT, Segal S. Extended [13C] galactose oxidation studies in patients with galactosemia. Mol Genet Metab. 2004;82(2):130-136. doi:10.1016/j. ymgme.2004.03.003

21. Lai K, Langley SD, Khwaja FW, Schmitt EW, Elsas LJ. GALT deficiency causes UDP-hexose deficit in human galactosemic cells. Glycobiology. 2003;13(4):285-294. doi:10.1093/glycob/cwg033

22. Panis B, Forget PP, van Kroonenburgh MJPG, et al. Bone metabolism in galactosemia. Bone. 2004;35(4):982-987. doi:10.1016/j.bone.2004.06.004

23. Thoden JB, Timson DJ, Reece RJ, Holden HM. Molecular structure of human galactose mutarotase. J Biol Chem. 2004;279(22):23431-23437. doi:10.1074/jbc.M402347200

24. Leslie N, Yager C, Reynolds R, Segal S. UDP-galactose pyrophosphorylase in mice with galactose-1-phosphate uridyltransferase deficiency. Mol Genet Metab. 2005;85(1):21-27. doi:10.1016/j.ymgme.2005.01.004 
25. Abraham HD, Howell RR. Hepatic uridine diphosphate galactose pyrophosphorylase. J Biol Chem. 1969;5(3): 545-550.

26. Shin YS, Niedermeier HP, Endres W, Schaub J, Weidinger S. Agarose gel isoelectrofocusing of UDPgalactose pyrophosphorylase and galactose-1-phosphate uridyltransferase. Developmental aspect of UDP-galactose pyrophosphorylase. Clin Chim Acta. 1987;166(1):27-35. doi:10.1016/0009-8981(87)90191-4

27. Bossolan G, Trindade CEP, Barreiros RC. Blood galactose and glucose levels in mothers, cord blood, and 48-hour-old breast-fed full-term infants. Neonatology. 2007;91(2):121126. doi:10.1159/000097129

28. Brown LD, Cavalli C, Harwood JEF, et al. Plasma concentrations of carbohydrates and sugar alcohols in term newborns after milk feeding. Pediatr Res. 2008;64(2):189193. doi:10.1203/PDR.0b013e3181761888

29. Lv Y, Yu G. Galactose: chemical structure, dietary sources and clinical significance. In: Pomin VH, ed. Galactose: structure and function in biology and medicine. New York, NY: Nova Science Publishers, Inc.; 2014:1-24.

30. Naranjo ARC. Desarrollo de un modelo computacional como plataforma para el estudio de la galactosemia clásica. Bogotá, DC: Carrera de Nutrición y Dietética, Facultad de Ciencias, Pontificia Universidad Javeriana; 2017. https:// repository.javeriana.edu.co/handle/10554/33778. Accessed June 27, 2021.

31. Van Calcar SC, Bernstein LE, Rohr FJ, Scaman CH, Yannicelli S, Berry GT. A re-evaluation of life-long severe galactose restriction for the nutrition management of classic galactosemia. Mol Genet Metab. 2014;112(3):191-197. doi:10.1016/j.ymgme.2014.04.004

32. Ribeiro AC, Silva MJ, Figueira ME. Galactose: diet and its implication in galactosémia. In: Pomin V, ed. Galactose: structure and function in biology and medicine. 1st ed. New York, NY: Nova Science Publishers, Inc.; 2014:47-74.

33. Walter JH, Fridovich-Keil JL. Galactosemia. In: Valle DL, Antonarakis S, Ballabio A, Beaudet AL, Mitchell GA. eds. The Online Metabolic and Molecular Bases of Inherited Disease. New York, NY: McGraw-Hill; 2019. doi:10.1036/ ommbid.381

34. Coss KP, Treacy EP, Cotter EJ, et al. Systemic gene dysregulation in classical Galactosaemia: Is there a central mechanism? Mol Genet Metab. 2014;113(3):177-187. doi:10.1016/j.ymgme.2014.08.004

35. Al-Essa M, Dhaunsi GS, Al-Qabandi W, Khan I. Impaired NADPH oxidase activity in peripheral blood lymphocytes of galactosemia patients. Exp Biol Med (Maywood). 2013;238(7):779-786. doi:10.1177/1535370213480692
36. Jumbo-Lucioni PP, Hopson ML, Hang D, Liang Y, Jones DP, Fridovich-Keil JL. Oxidative stress contributes to outcome severity in a Drosophila melanogaster model of classic galactosemia. Dis Model Mech. 2013;6(1):84-94. doi:10.1242/dmm.010207

37. Berry GT, Wehrli S, Reynolds R, et al. Elevation of erythrocyte redox potential linked to galactonate biosynthesis: elimination by Tolrestat. Metabolism. 1998;47(11):14231428. doi:10.1016/s0026-0495(98)90317-1

38. Cuatrecasas P, Segal S. Galactose conversion to D-xylulose: an alternate route of galactose metabolism. Science. 1966;153(3735):549-551. doi:10.1126/science.153.3735.549

39. Schadewaldt P, Hammen H-W, Stolpmann S, Kamalanathan L, Wendel U. Galactonate determination in urine by stable isotope dilution gas chromatography-mass spectrometry. J Chromatogr B Analyt Technol Biomed Life Sci. 2004;801(2):249-255. doi:10.1016/j.jchromb.2003.11.020

40. Yager CT, Chen J, Reynolds R, Segal S. Galactitol and galactonate in red blood cells of galactosemic patients. Mol Genet Metab. 2003;80(3):283-289. doi:10.1016/j. ymgme.2003.08.021

41. Yager C, Wehrli S, Segal S. Urinary galactitol and galactonate quantified by isotope-dilution gas chromatography-mass spectrometry. Clin Chim Acta. 2006;366(1-2):216-224. doi:10.1016/j.cca.2005.10.015

42. Rubio-Agusti I, Carecchio M, Bhatia KP, et al. Movement disorders in adult patients with classical galactosemia. Mov Disord. 2013;28(6):804-810. doi:10.1002/mds.25348

43. van Erven B, Jansma BM, Rubio-Gozalbo ME, Timmers I. Exploration of the brain in rest: resting-state functional MRI abnormalities in patients with classic galactosemia. Sci Rep. 2017;7(1):9095. doi:10.1038/s41598-017-09242-w

44. Welsink-Karssies MM, Schrantee A, Caan MWA, et al. Gray and white matter are both affected in classical galactosemia: an explorative study on the association between neuroimaging and clinical outcome. Mol Genet Metab. 2020;131(4):370-379. doi:10.1016/j.ymgme.2020.11.001

45. Doyle CM, Channon S, Orlowska D, Lee PJ. The neuropsychological profile of galactosaemia. J Inherit Metab Dis. 2010;33(5):603-609. doi:10.1007/s10545-010-9154-y

46. Welsink-Karssies MM, Oostrom KJ, Hermans ME, et al. Classical galactosemia: neuropsychological and psychosocial functioning beyond intellectual abilities. Orphanet J Rare Dis. 2020;15(1):42. doi:10.1186/s13023-019-1277-0

47. Treacy EP, Vencken S, Bosch AM, et al. Abnormal N-glycan fucosylation, galactosylation, and sialylation of IgG in adults with classical galactosemia, influence of dietary galactose intake. JIMD Rep. 2021;61(1):76-88. doi:10.1002/jmd2.12237 
48. Gaunitz S, Tjernberg LO, Schedin-Weiss S. The N-glycan profile in cortex and hippocampus is altered in Alzheimer disease. J Neurochem. 2021;159(2):292-304. doi:10.1111/ jnc. 15202

49. Colhoun HO, Gozalbo EMR, Bosch AM, et al. Fertility in classical galactosaemia, a study of N-glycan, hormonal and inflammatory gene interactions. Orphanet J Rare Dis. 2018;13(1):164. doi:10.1186/s13023-018-0906-3

50. van Erven B, Welling L, van Calcar SC, et al. Bone health in classic galactosemia: systematic review and meta-analysis. JIMD Rep. 2017;35:87-96. doi:10.1007/8904_2016_28

51. van Erven B, Römers MMM, Rubio-Gozalbo MER. Revised proposal for the prevention of low bone mass in patients with classic galactosemia. JIMD Rep. 2014;17:41-46. doi:10.1007/8904_2014_331

52. Van Calcar SC, Bernstein LE, Rohr FJ, Yannicelli S, Berry GT, Scaman CH. Galactose content of legumes, caseinates, and some hard cheeses: implications for diet treatment of classic galactosemia. J Agric Food Chem. 2014;62(6):13971402. doi:10.1021/jf404995a

53. Portnoi PA, Macdonald A. Determination of the lactose and galactose content of cheese for use in the galactosaemia diet. J Hum Nutr Diet. 2009;22(5):400-408. doi:10.1111/j.1365277X.2009.00948.x

54. Bosch AM. Classic galactosemia: dietary dilemmas. J Inherit Metab Dis. 2011;34(2):257-260. doi:10.1007/s10545-0109157-8

55. Gross KC, Acosta PB. Fruits and vegetables are a source of galactose: implications in planning the diets of patients with Galactosaemia. J Inherit Metab Dis. 1991;14(2):253258. doi:10.1007/BF01800599

56. Gropper SS, Weese JO, West PA, Gross KC. Free galactose content of fresh fruits and strained fruit and vegetable baby foods: more foods to consider for the galactose-restricted diet. J Am Diet Assoc. 2000;100(5):573-575. doi:10.1016/ s0002-8223(00)00175-9

57. Hartnett C, Kim H-O, Scaman CH. Effect of processing on galactose in selected fruits. Can J Diet Pract Res. 2007;68(1):46-50. doi:10.3148/68.1.2007.46

58. Kim H-O, Hartnett C, Scaman $\mathrm{CH}$. Free galactose content in selected fresh fruits and vegetables and soy beverages. J Agric Food Chem. 2007;55(20):8133-8137. doi:10.1021/ jf071302o

59. Scaman CH, Jim VJW, Hartnett C. Free galactose concentrations in fresh and stored apples (Malus domestica) and processed apple products. J Agric Food Chem. 2004;52(3):511-517. doi:10.1021/jf034643k

60. Acosta PB, Gross KC. Hidden sources of galactose in the environment. Eur J Pediatr. 1995;154(7 Suppl 2):S87-92. doi:10.1007/BF02143811
61. Adam S, Akroyd R, Bernabei S, et al. How strict is galactose restriction in adults with galactosaemia? International practice. Mol Genet Metab. 2015;115(1):23-26. doi:10.1016/j. ymgme.2015.03.008

62. Jumbo-Lucioni PP, Garber K, Kiel J, et al. Diversity of approaches to classic galactosemia around the world: a comparison of diagnosis, intervention, and outcomes. $J$ Inherit Metab Dis. 2012;35(6):1037-1049. doi:10.1007/ s10545-012-9477-y

63. Kerckhove KV, Diels M, Vanhaesebrouck S, et al. Consensus on the guidelines for the dietary management of classical galactosemia. Clin Nutr ESPEN. 2015;10(1):e1-e4. doi:10.1016/j.clnme.2014.10.001

64. Frederick AB, Cutler DJ, Fridovich-Keil JL. Rigor of nondairy galactose restriction in early childhood, measured by retrospective survey, does not associate with severity of five long-term outcomes quantified in 231 children and adults with classic galactosemia. J Inherit Metab Dis. 2017;40(6):813-821. doi:10.1007/s10545-017-0067-x

65. Krabbi K, Uudelepp M-L, Joost K, Zordania R, Õunap K. Long-term complications in Estonian galactosemia patients with a less strict lactose-free diet and metabolic control. Mol Genet Metab. 2011;103(3):249-253. doi:10.1016/j. ymgme.2011.03.023

66. Welling L, Bernstein LE, Berry GT, et al. International clinical guideline for the management of classical galactosemia: diagnosis, treatment, and follow-up. J Inherit Metab Dis. 2017;40(2):171-176. doi:10.1007/s10545-0169990-5

67. Coss KP, Byrne JC, Coman DJ, et al. IgG N-glycans as potential biomarkers for determining galactose tolerance in classical galactosaemia. Mol Genet Metab. 2012;105(2):212220. doi:10.1016/j.ymgme.2011.10.018

68. Delnoy B, Coelho AI, Rubio-Gozalbo ME. Current and future treatments for classic galactosemia. J Pers Med. 2021;11(2):75. doi:10.3390/jpm11020075

69. Cangemi G, Barco S, Barbagallo L, et al. Erythrocyte galactose-1-phosphate measurement by GC-MS in the monitoring of classical galactosemia. Scand J Clin Lab Invest. 2012;72(1):29-33. doi:10.3109/00365513.2011.622409

70. Palmieri M, Mazur A, Berry GT, et al. Urine and plasma galactitol in patients with galactose-1-phosphate uridyltransferase deficiency galactosemia. Metabolism. 1999;48(10):1294-1302. doi:10.1016/S0026-0495(99)90271-8

71. Berry GT, Palmieri M, Gross KC, et al. The effect of dietary fruits and vegetables on urinary galactitol excretion in galactose-1-phosphate uridyltransferase deficiency. J Inherit Metab Dis. 1993;16(1):91-100. doi:10.1007/BF00711320

72. Timson DJ. Purple sweet potato colour--a potential therapy for galactosemia? Int J Food Sci Nutr. 2014;65(4):391-393. doi:10.3109/09637486.2013.860586 
73. Demirbas D, Coelho AI, Rubio-Gozalbo ME, Berry GT. Hereditary galactosemia. Metabolism. 2018;83:188-196. doi:10.1016/j.metabol.2018.01.025

74. Crespo C, Eiroa H, Otegui MI, Bonetto MC, Chertkoff L, Gravina LP. Molecular analysis of GALT gene in Argentinian population: correlation with enzyme activity and characterization of a novel Duarte-like allele. Mol Genet Metab Rep. 2020;25:100695. doi:10.1016/j. ymgmr.2020.100695

75. Kisa PT, Kose M, Unal O, et al. Clinical and molecular characteristics and time of diagnosis of patients with classical galactosemia in an unscreened population in Turkey. J Pediatr Endocrinol Metab. 2019;32(7):675-681. doi:10.1515/jpem-2018-0457

76. Yuzyuk T, Wilson AR, Mao R, Pasquali M. Galactose1-Phosphate Uridyltransferase activities in different genotypes: a retrospective analysis of 927 samples. J Appl Lab Med. 2018;3(2):222-230. doi:10.1373/jalm.2017.025536

77. Lai K, Langley SD, Singh RH, Dembure PP, Hjelm LN, Elsas LJ. A prevalent mutation for galactosemia among black Americans. J Pediatr. 1996;128(1):89-95. doi:10.1016/ s0022-3476(96)70432-8

78. Yang YP, Corley N, Garcia-Heras J. Molecular analysis in newborns from Texas affected with galactosemia. Hum Mutat. 2002;19(1):82-83. doi:10.1002/humu.9005

79. Garcia EG, García BB, Estrada ÚC, Cruz AL. Galactosemia: diagnóstico de 5 casos con deficiencia de transferasa. Rev Cubana Pediatr. 2001;73(2):75-80.

80. Mahmood U, Imran M, Naik SI, et al. Detection of common mutations in the GALT gene through ARMS. Gene. 2012;509(2):291-294. doi:10.1016/j.gene.2012.08.010

81. Berry GT. Galactosemia: When is it a newborn screening emergency? Mol Genet Metab. 2012;106(1):7-11. doi:10.1016/j.ymgme.2012.03.007

82. Maratha A, Stockmann H, Coss KP, et al. Classical galactosaemia: novel insights in IgG N-glycosylation and N-glycan biosynthesis. Eur J Hum Genet. 2016;24(7):976984. doi:10.1038/ejhg.2015.254
83. Carlock G, Fischer ST, Lynch ME, et al. Developmental outcomes in duarte galactosemia. Pediatrics. 2019;143(1):e20182516. doi:10.1542/peds.2018-2516

84. Fridovich-Keil JL, Gambello MJ, Singh RH, Sharer JD. Duarte variant galactosemia. In: Adam MP, Ardinger $\mathrm{HH}$, Pagon RA, et al., eds. GeneReviews ${ }^{\circledast}$. Seattle, WA: University of Washington; 2014. https://pubmed.ncbi.nlm. nih.gov/25473725/. Accessed December 14, 2020.

85. McCandless SE. Answering a question older than most pediatricians: what to do about duarte variant galactosemia. Pediatrics. 2019;143(1):e20183292. doi:10.1542/peds.20183292

86. Waisbren SE, Tran C, Demirbas D, et al. Transient developmental delays in infants with Duarte-2 variant galactosemia. Mol Genet Metab. 2021;134(1-2):132-138. doi:10.1016/j.ymgme.2021.07.009

87. Welling L, Boelen A, Derks TGJ, et al. Nine years of newborn screening for classical galactosemia in the Netherlands: effectiveness of screening methods, and identification of patients with previously unreported phenotypes. Mol Genet Metab. 2017;120(3):223-228. doi:10.1016/j. ymgme.2016.12.012

88. Kotb MA, Mansour L, Basanti CWS, et al. Pilot study of classic galactosemia: neurodevelopmental impact and other complications urge neonatal screening in Egypt. J Adv Res. 2018;12:39-45. doi:10.1016/j.jare.2018.02.001

89. Lak R, Yazdizadeh B, Davari M, Nouhi M, Kelishadi R. Newborn screening for galactosaemia. Cochrane Database Syst Rev. 2017;12(12):CD012272. doi:10.1002/14651858. CD012272.pub2

90. Pyhtila BM, Shaw KA, Neumann SE, Fridovich-Keil JL. Newborn screening for galactosemia in the united states: looking back, looking around, and looking ahead. In: Zschocke J, Gibson KM, Brown G, Morava E, Peters V, eds. JIMD Reports. Berlin, Heidelberg: Springer; 2014:79-93. v. 15.

91. ClinicalTrials.gov. Galactosemia, Classic. https://clinical trials.gov/ct $2 /$ results? cond $=$ Galactosemia $\% 2 \mathrm{C}+$ Classic \&term $=\& c n t r y=\&$ state $=\&$ city $=\&$ dist $=$ 